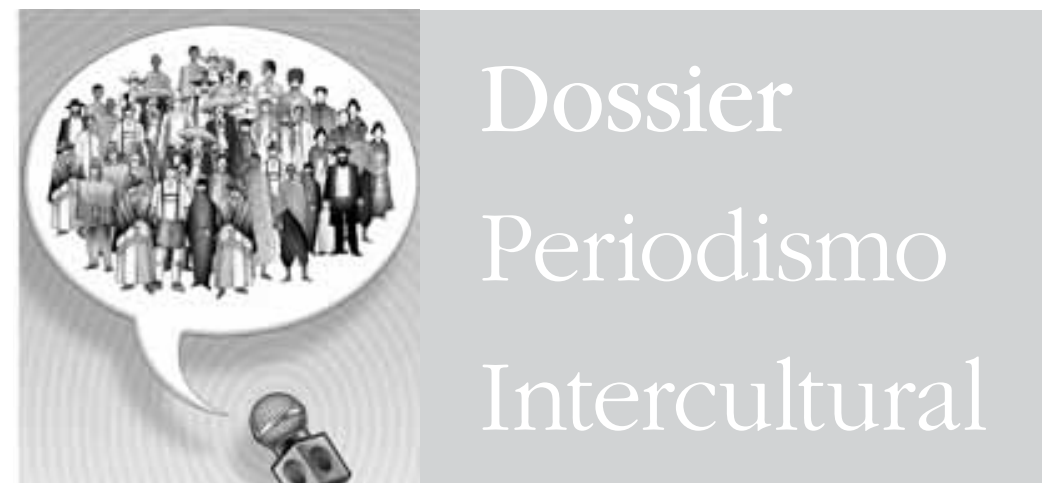

\title{
Indagaciones interculturales sobre orígenes y religiones en el humor periodístico
} Intercultural Questions about Origins and Religions in Journalistic Humor

DRA. ESTRELLA ISRAEL, Universidad CEU-Cardenal Herrera. Valencia, España. (estrella.univdgmail.com) DRA. MARIA JOSE POU, Universidad CEU-Cardenal Herrera. Valencia. España.(mpouQuch.ceu.es)

- Recibido: 22/08/2011. Aceptado: 14/11/2011

\section{RESUMEN}

El humor periodístico -las denominadas viñetas de prensa- constituye uno de los más peculiares géneros periodísticos de opinión. Su componente gráfico, el habitual uso del humor y la apertura a la libre interpretación le proporcionan un carácter singular con un alto grado de eficacia persuasiva. El objetivo de este artículo es procesar esta modalidad comunicativa en relación con las distorsiones interculturales. Este estudio explora los elementos de análisis aplicables en el ámbito de la representación de la diferencia: las variables "origen", vinculada con la inmigración, y la denominada "religión" presentan usos contrapuestos cuando ponen el acento en los estereotipos y pierden la dimensión social.

Palabras clave: Humor, viñeta, prensa, interculturalidad, inmigración, religión

\section{ABSTRACT}

The journalistic humor - called cartoons-is one of the most peculiar journalistic way to express opinions. Graphic elements, uses of the humor and the opening to the free interpretation provide a singular character with a high degree of persuasive efficiency. The aim is to process this communicative modality in relation with the intercultural distortions. This study explores the elements of significance in this area of the representation of the difference. The variables "origin" linked with the immigration and the "religion" present opposite uses when they focus in the stereotypes and loose the social dimension.

Keywords: Humor, cartoon, press, interculturality, immigration, religion 


\section{INTRODUCCIÓN}

"Mientras las ramas se pelean, las raíces se abrazan", proverbio senegalés

Las imágenes de la alteridad en los medios de comunicación constituyen un tema central en la investigación mediática que remite principalmente a tres ámbitos en el campo de los medios de comunicación. El primero incluye el fenómeno de la representación comunicativa o informativa, persuasiva o de ficción o, por expresarlo con otra terminología, la industria de los contenidos; el segundo, el acceso profesional, es decir, la presencia de personas pertenecientes a minorías étnicas o culturales en las empresas de comunicación; el tercero abarca la perspectiva de los medios propios creados por las minorías para satisfacer necesidades específicas de las poblaciones. Estas posibilidades se conectan con Internet, con el periodismo participativo y especialmente con canales o redes específicas.

El trabajo que se presenta en estas páginas aborda el primero de estos ámbitos, aquel que se refiere a los límites y consecuencias de la representación comunicativa. Se vincula, especialmente, con la preocupación por la creación y difusión de estereotipos cuya presencia queda fortalecida por el uso del humor. Nos centramos, particularmente, en la viñeta de prensa para indagar si la imagen del otro que se proyecta llega a potenciar un discurso discriminatorio en razón de diversos factores.

El objetivo es ofrecer una serie de elementos analíticos para determinar la existencia de contenidos estereotipadores en las viñetas cómicas en la prensa diaria -principalmente españolaa través de ejemplos relacionados con dos de los indicadores diferenciales más comunes -origen y religión-, así como ofrecer pautas de reflexión acerca de la responsabilidad del profesional en su desarrollo con el fin de lograr una comunicación y una información verdaderamente intercultural.

\section{ESTEREOTIPOS Y ALTERIDAD.}

"No podemos analizar seriamente el racismo contemporáneo sin interrogarnos sobre la influencia eventual de los medios de comunicación en la progresión, la difusión, pero también en la regresión del fenómeno" (Wieviorka, 1998, p. 113).

El hecho de que una sociedad o un espacio geográfico sean multiculturales no garantiza que en él se viva la interculturalidad. Al contrario, esta diversidad presagia todo tipo de conflictos. Estamos inmersos en un proceso de movilidad e incluso de movilizaciones, que se vinculan con los desplazamientos migratorios, pero también con los pueblos indígenas o las minorías religiosas; situaciones de conflictos planetarios y enfrenta- mientos localizados forman parte del temario de la actualidad internacional. Las imágenes públicas de estos encuentros y desencuentros, perfiles y retratos entran dentro de unos mecanismos de estereotipación-identificación muy variados, que generalmente asocian la desigualdad social y la diferencia, en una amalgama compleja.

El universo digital -Internet y las redes sociales- ha venido a complicar y dificultar las necesarias matizaciones y ángulos de selección y jerarquización de la información periodística. Leyes de mercado, estrategias de fidelización y mimetismos marcan el panorama que se pretende intercultural, ya que en un mundo lleno de complejidades y ambigüedades, estamos constantemente buscando caminos para confrontar y simplificar la confusión de la vida cotidiana.

Los estereotipos tienen una función importante en tanto que constituyen un modo económico de ver y de narrar el mundo. Sin embargo, el uso de estereotipos puede resultar especialmente peligroso cuando se trata de una simplificación sistemática y, sobre todo, despreciativa. Se dice que participamos en el proceso de estereotipación cuando incluimos nociones preconcebidas en la representación mediática de otros grupos. Estamos, entonces, ante los ruidos interculturales por estereotipos y prejuicios.

En este proceso, la variedad de etiquetas e imágenes preestablecidas se extiende a todos los sectores de la interacción social. Goffman (1986, p. 150) aborda los estigmas, entendidos como atributos negativizadores que se manifiestan en las relaciones entre diferentes. El estereotipo no es neutral, afecta a nuestra percepción de la realidad e históricamente ha constituido una importante fuente de control social.

\subsection{DESIGUALDAD E INVISIBILIDAD}

En la información periodística, dos grandes parámetros definen la representación de los diferentes: por un lado la ausencia, la invisibilidad y, por otro, su vinculación con argumentos o acontecimientos de desviación y negatividad. Estas situaciones se definen como ruidos interculturales. Como ejemplo cabe citar el fenómeno de la conceptualización que se produce cuando, de acuerdo con la teoría del etiquetaje, se nombra a una persona de acuerdo con el país de origen, el color de su piel, su cultura, su pertenencia étnica, su creencia religiosa y no es necesario para la comprensión del acontecimiento. Códigos deontológicos y libros de estilo proponen que no se etnifiquen algunos comportamientos, a veces como una mímesis respecto a la nota policial que conlleva la asimilación de determinados hechos delictivos con las definiciones 
de nacionalidades extranjeras. El factor religioso, a partir del 11 de septiembre de 2001, ha entrado también de lleno en el registro periodístico.

Es evidente que detrás de las palabras inmigrantes, inmigración, extranjeros, se esconden realidades muy diversas con matices y perfiles diferenciados. Un estudio sobre la representación de los inmigrantes latinoamericanos -ecuatorianos, argentinos y colombianos-, en la prensa española realizado por Jessica Retis (2004, p. 134), concluye que los inmigrantes colombianos, a diferencia de los ecuatorianos, son vistos como otros, como los enemigos que desestabilizan la vida civil. Un proceso que consiste en desplazar la imagen de un determinado país de origen hacia el que reside en España. Casos de mujeres víctimas de la violencia masculina, de menores insertos en la marginalidad urbana o bien de conflictos e incluso atentados que se traducen en el imaginario popular, según el informe publicado por la Red Europea de Información sobre el Racismo y la Xenofobia (RAXEN) ${ }^{1}$, en la definición de la inmigración ilegal con la delincuencia y los atentados.

Además de la conceptualización, los ruidos o distorsiones más frecuentes en la representación periodística de los otros son la tematización, la argumentación con una divisoria estigmatizadora, y la desviación y negatividad. También hay que considerar adaptaciones locales que condicionan incluso la definición de esos otros.

Esa representación estereotipada alcanza también a los denominados perfiles nacionales, especialmente los referidos a los países vecinos con los que se comparte una historia conflictiva. A la hora de estudiar los estereotipos nacionales Hélène Duccini (2004, pp. 67-68) considera que hay que tener en cuenta dos aspectos: por un lado, que siempre somos extranjeros para alguien y, por otro, que las identidades nacionales se han constituido lentamente y en ocasiones como resultado de conflictos y guerras entre vecinos.

\section{VIÑETAS, CARICATURAS, HUMOR PERIODÍSTICO}

Las viñetas o dibujos aparecen en los periódicos como géneros argumentativos. El primer problema aparece en la definición terminológica. Algunos hablan de viñetas, otros de humor gráfico; en otros medios simplemente se define con el nombre del autor, pero lo que resulta común, mayoritariamente, es que la aparición de los dibujos que representan una situación o expresan una opinión se encuentre habitualmente -aunque no exclusivamente- en las páginas dedicadas a la argumentación de los periódicos. Por tanto es un producto eminentemente periodístico, que se identifica con su autor. (Cánovas, 2003, p. 548)
Tanto Luisa Santamaría (1990, p. 81) como Emy Armañanzas y Díaz Noci (1996, pp. 111 y ss.) abordan este tema bajo el epígrafe "La opinión iconográfica". Consideran que en España es en las páginas de Opinión de los diarios donde las ilustraciones son o bien de carácter iconográfico -retratos, caricaturas- o viñetas de humor con o sin texto.

La viñeta -como señala Gubern (1997)- es un producto cultural visible, un ente fabricado por el ser humano específicamente para la comunicación visual de la subcategoría de las imágenes icónicas (dibujo, pintura, escultura, maquetas, decorado, fotografía, cine, televisión, video). En su origen, se trata de un dibujo o ilustración impreso que sirve para mejorar estéticamente las páginas de la prensa. Debe su nombre a los grabados de adorno, a base de racimos de uvas, que se incluían como elementos decorativos en los más variados impresos. De carácter humorístico en muchos casos y también a base de caricaturas, cuando se publican en serie componen la tira cómica o cómic (Benito, p. 2001).

El libro de estilo del diario El País al referirse a las "Ilustraciones humorísticas" establece que "los dibujos o tiras de humor son considerados elementos de opinión, y, por tanto, responden al criterio de sus autores. No obstante, no se permitirán los chistes que ofendan la intimidad de las personas ni que ofrezcan imágenes desagradables".

Dentro del apartado de imágenes que pueden aparecer en un diario destacan las fotografías, le siguen las ilustraciones y la infografía. En el apartado de Ilustraciones se incluyen retratos, representación gráfica de personas que algunos diarios utilizan en los artículos de opinión para dar una imagen del autor; los chistes gráficos, que hacen por lo general alusión a alguna situación de actualidad desde un punto de vista cómico o ridiculizante. En España se emplean en las páginas de opinión y también en distintas secciones. Forges, Gallego y Rey, Ferreres, Mingote, Ricardo y Nacho, El Roto y Peridis son algunos de los dibujantes reconocidos en España dentro de este género. En las caricaturas se trata de un dibujo satírico en el que se deforman las facciones y el aspecto de algún personaje de la actualidad. (Armentia, Caminos, 2003, p. 171)

La caricatura periodística, igual que otros materiales de opinión, se relaciona con la noticia, luego contendrá significaciones informativas, de opinión, entretenimiento y propaganda con efectos pragmáticos. En qué medida cumple estas funciones es algo que no se puede establecer teóricamente para todos los casos, sino en situaciones determinadas, respecto a un receptor también concreto.[...] puede convenirse en que la caricatura es un comunicado iconográfico impreso, de índole subjetiva, mediante el cual se
1 Los informes Raxen están editados por Movimiento contra la Intolerancia. Accesible en http://www. movimientocontralaintolerancia. com/html/raxen/raxen. asp. Véase el número 37 (2008) sobre "Las mentiras de la xenofobia" http://www. movimientocontralaintolerancia. com/download/raxen/37/ RAX37.pdf

2 El País, (1990)Libro de Estilo, Aguilar, p.58 
3 Josep Lluis Gómez Mompart (2010) se ha referido al concepto genérico de "risa periodística", donde engloba el humor y la sátira desde la prensa moderna hasta Internet. VVAA. La risa periodística, Valencia, Tirant Lo Blanch.

4 Véase el blog de Ramón Lobo en el diario "El País" http:// blogs.elpais.com/aguasinternacionales/2011/05/ humor-frente-a-politica.html Fecha de consulta: 25 mayo 2011 semantizan las interpretaciones de una realidad, desfigurándola deliberadamente. La crítica política por este medio, tiene variantes que van desde el elogio y propaganda hasta la crítica acre, pasando por formas parecidas a las del artículo editorial". (Rivadeneira, 1975, p. 239)

La caricatura política no es una información ni un retrato: en esencia es un medio para expresar una opinión. Es la expresión firmada de una opinión personal.

La regla principal en el humor gráfico es que todo debe ser dicho de modo indirecto. La situación que se presenta es casi siempre tan imposible e inverosímil que resulta claro que solo permite una lectura figurada. Según Peñamarín (1997) la estrategia utilizada para conducir ese decir indirecto es la metáfora. Aquello a lo que la caricatura o viñeta se refiere es visto desde una perspectiva metafórica y esta se sustenta sobre un fértil sustrato de mitos, leyendas y referentes culturales (referentes históricos y también actuales) que brindan la radio y la televisión, que componen nuestro acervo e imaginario popular.

La viñeta es uno de los géneros presentes en Internet, a diferencia de los grandes géneros clásicos como el artículo o la columna $^{3}$. Presenta en la red los mismos rasgos que tiene en la prensa impresa tradicional, en cambio el humor se ha desarrollado con adaptaciones (montajes fotográficos) o con rasgos propios como la animación y la interactividad (videos, animaciones y juegos). Lo que llama la atención es que estas innovaciones se han ido produciendo especialmente en páginas web que, en muchos casos, nada tienen que ver con sitios de contenido periodístico

Natividad Abril se refiere al humor como recurso en el periodismo de opinión y considera que:

.nadie discute hoy en día el enorme poder del humor -ironía o paradoja- ni el papel irremplazable que juega a la hora de cuestionar a la razón, de desbancar ideas y creencias consideradas inamovibles; el poder para incitar y sugerir nuevos caminos de acceso al conocimiento; su enorme capacidad para comunicar, para llegar a las personas que leen el periódico, ni su aplicación en todos los géneros, desde la crítica al editorial. (Abril, 1999, p. 112)

Además aclara que "por regla general las ilustraciones que no son meras acompañantes de un texto hacen referencia a uno de los temas más candentes del día, tema que acostumbra a coincidir con el editorial del día" (p. 164).

Según Ramón Lobo $^{4}$, los dibujantes expresan en muy pocas palabras, o en ninguna, lo que nadie se atreve o es capaz de decir con muchas. Una buena viñeta deja muda a una crónica o un reportaje porque una buena viñeta es un puñetazo sobre la mesa. En una sociedad gris, secuestrada por un lenguaje burocrático, un puñetazo en la mesa despierta a cualquiera. Los cartoonists, como se dice en Reino Unido, donde cobran fuerza en el siglo XVIII, son parte esencial en la tradición del buen periodismo escrito, sea periódico, revista o Internet. El buen periodismo siempre ha sido inteligencia y honestidad al servicio de una noticia, de una historia, para contar o explicar mejor lo que sucede a nuestro alrededor.

\subsection{OPINAR A TRAVÉS DEL HUMOR GRÁFICO}

Todavía resuenan los ecos del conflicto generado por las viñetas periodísticas de Jyllands Posten y su réplica globalizada en el concurso iraní sobre el Holocausto. Estos debates están sin duda en el imaginario colectivo y simultáneamente confrontan el tema de la libertad de expresión y de creación artística y el respeto a la identidad de los otros, con los símbolos culturales y/o religiosos. Es un hecho que las caricaturas de políticos se portan en las manifestaciones globalizadas. Su poder político propagandístico ha sido evidente a lo largo de la historia de la comunicación de masas. "Benjamín Franklin publicó en 1754 en la Pennsylvania Gazette, un famoso dibujo alegórico subtitulado "Join or die" (Unirse o morir) proclamando la unidad de las trece colonias británicas para formar los Estados Unidos, y en el que hacía uso del globo o bocadillo, un indicador de locución derivado de las filacterias de las pinturas medievales. Con este dibujo se inauguraba la gran era del llamado cartoon político anglosajón, edad de oro que se extiende desde el último tercio del siglo XVIII hasta mediados del siglo XIX" (Gubern. 1997, p. 71)

El producto viñeta de determinados medios islamistas inunda hoy la red, nos retrotrae a las caricaturas judeófobas muy frecuentes en las primeras décadas del siglo pasado en Europa. La opinión iconográfica ha sido estudiada desde el punto de vista de la crítica política y de la sátira, también como elemento de propaganda o de ingenio reivindicativo de libertad. La viñeta es atípica, porque combina recursos gráficos y textuales -cuando no exclusivamente gráficos-, a menudo en forma de dibujo, pero también utilizando otro tipo de grafismo, en especial gracias a la plena utilización de las tecnologías en el tratamiento gráfico en prensa

La tira cómica, el chiste o la viñeta son parte del periodismo desde hace mucho tiempo y han demostrado tener una gran fuerza en la formación de la opinión pública. Es la persuasión por la vía del delectare que busca la diversión, el deleite frente a la categoría del docere que se basa en la demostración intelectual y, se di- 
rige por tanto a la razón o la del movere que se dirige a los afectos a través de apelaciones apasionadas al público. (Herrero. 1997, pp. 123-124)

A veces el delectare y el movere van de la mano propagandística, en la línea descrita por Freud respecto a la víctima del chiste. Pero las viñetas, con todos sus componentes artísticos y creativos, de relectura iconográfica, también son una ocasión o incluso una fuente distorsionadora reproductora de viejos y de nuevos estigmas.

En ella se semantizan las interpretaciones de una realidad, desfigurándola deliberadamente, lo que ha llevado en ocasiones a conflictos como el del Jyllands Posten. Según Victoria Camps,

las expresiones discriminatorias o excluyentes ofenden a los discriminados y a los excluidos. A los inmigrantes no los hace felices que se identifique a un delincuente como marroquí o ecuatoriano, ni que se hable de inmigración, en general, como si todas las personas inmigradas fueran idénticas. (2007, p. 5)

En ocasiones, el problema no es solo la descontextualización sino también la burla, el desprecio, la ridiculización de las víctimas (personajes identificables o no sobre los que el autor opina) o de las situaciones. Esa reducción de sentido es lo que provoca o profundiza los estereotipos. Por tanto, para una comunicación verdaderamente intercultural ${ }^{5}$, es necesario localizar los focos de producción de estereotipos, si los hubiera, en los formatos de opinión gráfica.

\subsection{IDENTIDADES CULTURALES}

Las viñetas también han sido abordadas desde el punto de vista de la identidad cultural. Al respecto podemos citar algunos trabajos en torno al género, como el de Xavier Laborda sobre Forges, el de María Antonia Díaz sobre la imagen de la mujer en el cómic o la amplia producción latinoamericana entre la que figura el trabajo de Roland Álvarez sobre las ilustraciones de humor y la masculinidad hegemónica tradicional. También las viñetas han sido ampliamente tratadas en el terreno educativo, tal es la iniciativa del Grupo Comunicar en España o distintos equipos de profesorado, dentro de una pedagogía intercultural.

Alejandro Baer y Federico Zuckerman (2005, p. 77) señalan que el humor gráfico comunica siempre una reflexión referida al presente de los interlocutores, un presente marcado por la agenda política y social. Pero lo que se busca en el chiste gráfico no es la reproducción de los hechos, sino la introducción de una perspectiva que determine en su audiencia, a través del humor y el doble sentido, una particular interpretación de los acontecimientos que constituyen su referente.

Cristina Peñamarín (2002, p. 356) en "El humor gráfico del franquismo y la formación de un territorio translocal de identidad democrática" y en "Discursos e imágenes sobre la inmigración en El País" considera que el humor gráfico es un espacio muy adecuado para observar la dinámica social de contestación de los territorios impuestos como ámbito común al pensar y sentir de todos, y de apertura de nuevos procesos de territorialización en torno a otros referentes que se tratan de destacar y valorizar.

Este tipo de texto procura siempre crear una complicidad con su destinatario, que ha de entender algo que no está dicho explícitamente, sino sugerido a través de las palabras, el modo de pensar o de mirar propio de otro u otros, las cuales son burladas o desmentidas por el texto. El humor comienza a cuestionar los valores comúnmente aceptados, a resignificar los tópicos sociales, saca a la luz los tabúes e invierte las jerarquías de prestigio. Una de sus estrategias es la creación de tipos sociales, tanto positivos como negativos o ridículos. La peculiaridad de estos textos es que se propugnan valores y se realizan reflexiones que no tendrían cabida en los espacios tradicionales.

\subsection{EL TRIÁNGULO DEL HUMOR}

Para obtener respuestas relevantes en el análisis de los elementos que favorecen o perjudican la interculturalidad, entendida como cualidad de caracterización del otro, del diferente, debemos considerar, ante un producto comunicativo, los siguientes aspectos: el grupo y el medio de comunicación, la fecha de publicación, la firma, la ubicación espacial, el tema de actualidad general, el acontecimiento específico, la interrelación con el editorial, la jerarquización informativa y las variables socioculturales implicadas, entre ellas las más representativas: género, clase social, etnia, religión, origen, edad, capacidad, apariencia física, enfermedad y orientación sexual.

También es importante la dirección predominante, si el mensaje se dirige hacia el ambiente social o hacia el sistema político. La obra de Lorenzo Gomis, El medio media, La función política de la prensa (1987), es un clásico a la hora de caracterizar los espacios de la mediación política: editorial y viñeta. Hoy la mediación se produce en el temario global. Las posiciones editoriales trascienden las páginas tradicionales, pero el esquema de Gomis respecto al ambiente social y sistema político sigue siendo una pauta necesaria a la hora del análisis del también denominado chiste político.

Las viñetas responden a un triángulo: actor, lector y víctima. Unas son de desplazamiento y otras realistas, analógicas o de condensación. También podemos determinar si estamos ante
5 “Los estereotipos constituyen un modo establecido de reducir la riqueza de la realidad a unos modelos muy simples. El trabajo de filtrado de los estereotipos es socialmente necesario y aumenta al crecer el tamaño de las sociedades" (Israel, E., Comunicación y Periodismo en una sociedad global. Comunicar la diferencia, Trillas, Eduforma, 2006: 42). 
6 El Mundo. 4, 9.2010, con el título La bandera, el narco y una "polémica caricatura " se hace eco de las reacciones http://www.elmundo. es/america/2010/09/03/ mexico/1283474701.html. Fecha de consulta: 10 julio 2011

7 Isabel Ramos Rioja en La Vanguardia, "Reírse hasta de su sombra", una reflexión sobre el humor en los países árabes. Según la autora los más prolíficos son egipcios, libaneses y argelinos, mientras que temas como Dios, el profeta y el rey son intocables". 8 agosto 2010, p 6

8 Una caricatura que asocia al candidato presidencial con los movimientos islamistas radicales. http:// www.elconfidencial.com/ cache/2008/07/14/58 caricatura_obama_ataviado integrista_islamico_desata_ polemica.html. Fecha de consulta: 6 de julio 2011

9 "El New York Post se disculpa por la caricatura del chimpancé" en El Mundo 20 de febrero de 2009 http://www.elmundo. es/elmundo/2009/02/20/ comunicacion/1235106919.html Fecha de consulta: 9 de julio de 2011 un modelo referencial, cuando tiene apego a un acontecimiento o actor político particular, o bien conceptual, cuando lo que se pone en juego son valores o principios más generales.

Este modelo de análisis se enriquece cuando se realiza de una manera intertextual e internacional, para poner de relieve las estrategias discursivas y las adaptaciones locales. Como ejemplo podemos recordar la comparación en tres medios de sendas viñetas satíricas sobre los conflictos en los suburbios franceses a finales de 2005, que confirma que las viñetas son una mirada singular sobre los hechos de actualidad; un modo económico, reducido e instantáneo de interpretarla.

Las identidades nacionales también participan de esta perspectiva crítica. Es el caso de la polémica caricatura firmada por Daryl Cagle publicada en la página web de la cadena estadounidense MSNBC sobre la violencia en México, con una deformación intencionada de la bandera y con el águila tiroteada ${ }^{6}$.
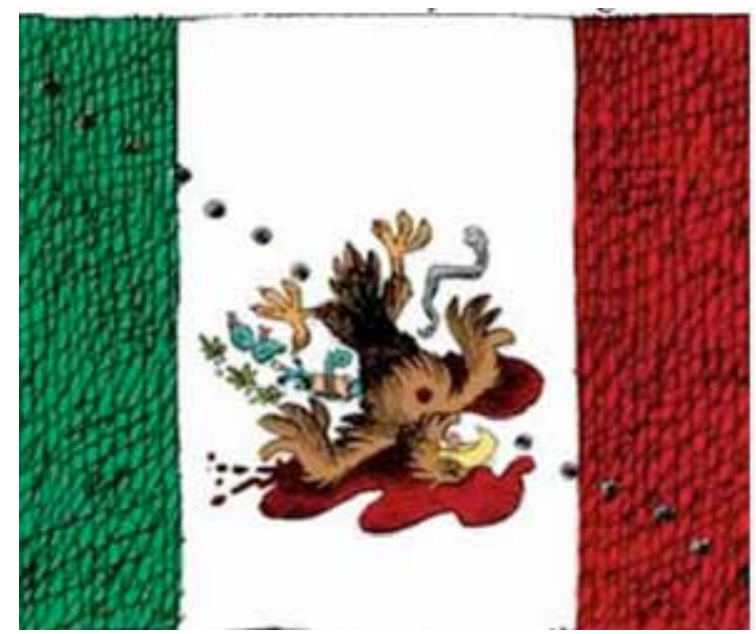

Caricatura sobre la violencia en México

En un artículo publicado por el diario La Vanguardia en referencia al humor en los países árabes, Isabel Ramos ${ }^{7}$ afirma: "Cada país tiene su blanco favorito. Así los saidi, saidi, como los llaman a los del Sur de Egipto para los cairotas, los sirios, para los libaneses; los marroquíes para los argelinos o los argelinos para los tunecinos. Al fin y al cabo, como los belgas para los franceses".

Pero las polémicas también afectan a las identidades y filiaciones políticas. Dos viñetas del New Yorker y del New York Post son criticadas por motivos diferentes; en el primero por la asociación de Obama con el islamismo, aunque la ilustración va acompañada por la leyenda "Las mentiras de campaña" y según su autor pretendía criticar los argumentos conservadores y no al entonces candidato a la Presidencia de los EEUU ${ }^{8}$.

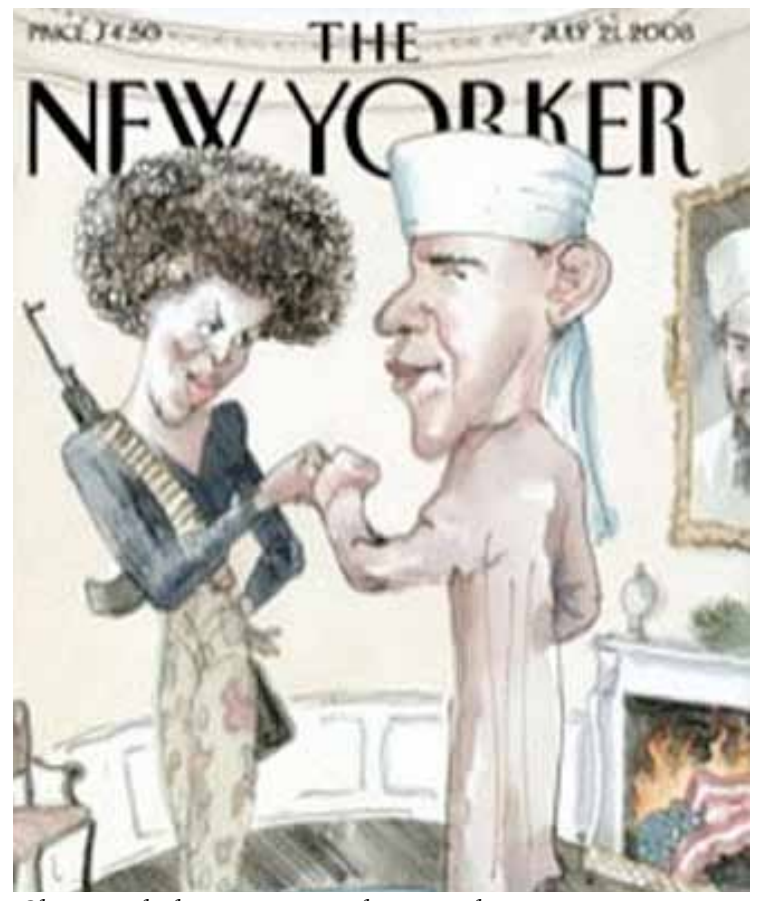

Obama y el islamismo según el New Yorker

Más clara, desde la óptica del discurso discriminatorio, es la imagen del New York Post en la que dos policías acribillan a un mono, por la ambigüedad del texto: "Tendrán que encontrar a otro para que escriba la próxima ley del estímulo". . Aunque la caricatura podría ser interpretada a partir de un acontecimiento reciente -un chimpancé fue tiroteado en Connecticut- otras lecturas asociaban al animal con el máximo mandatario estadounidense que la víspera había anunciado la ley del estímulo económico.

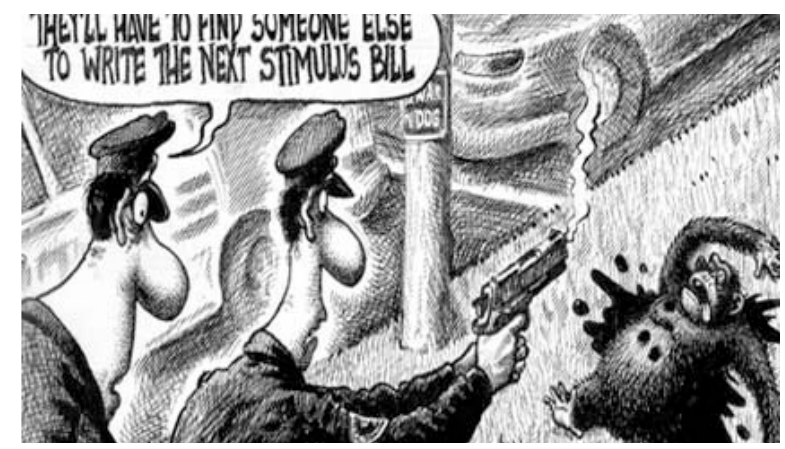

Caricatura del New York Post: ambigüedad del texto 


\subsection{ORÍGENES}

A la hora de analizar el reflejo de las personas inmigrantes en las viñetas de actualidad, podemos ir aún más lejos y determinar la presencia de símbolos antropomórficos o culturales relevantes e incluso fenómenos de transcodificación o hibridación.

En las siguientes viñetas referidas al episodio de la llegada de inmigrantes en pateras a las costas canarias, podemos aplicar la siguiente pauta de análisis: Modelo referencial, que alude directamente a un hecho de actualidad informativa, o Modelo conceptual, cuando trasciende el acontecimiento para abordar una problemática más general.

Otro aspecto a determinar es la dirección del mensaje (Gráfico 1), es decir si se dirige al sistema político, a la crítica política o bien opta por el ambiente social, es decir sensibilizar a la opinión pública sobre una situación determinada.

\section{Gráfico 1: Dirección del mensaje}

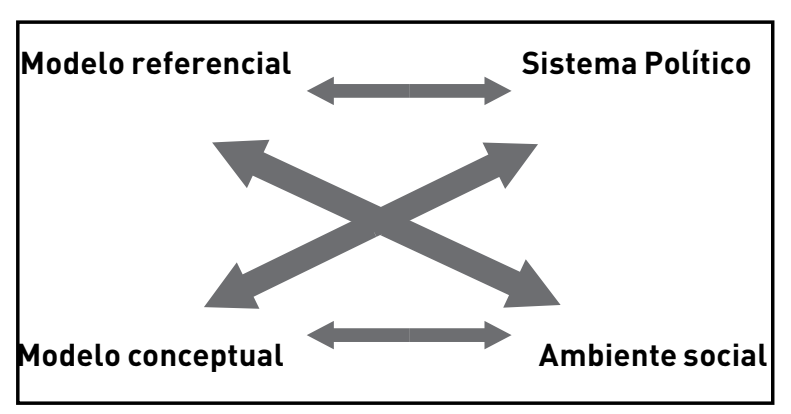

Fuente: elaboración propia

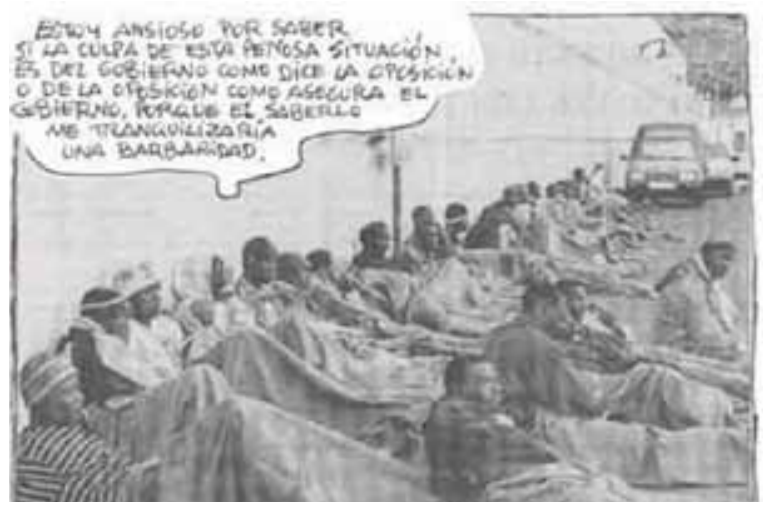

Mingote, ABC, 04/06/06. Modelo referencial hacia el sistema político

El dibujante Mingote, en el diario $A B C$, reproduce la imagen fotográfica de los inmigrantes. Estamos ante un modelo referencial, que a través de un bocadillo critica la actuación de los políticos, tanto de los gobernantes como de la oposición, a través de la ironía entre las declaraciones y las realidades. En el mismo diario, Martín Morales realiza también su crítica al acontecimiento con la caricatura del ministro que ata las manos de los inmigrantes y los repatría a Senegal.

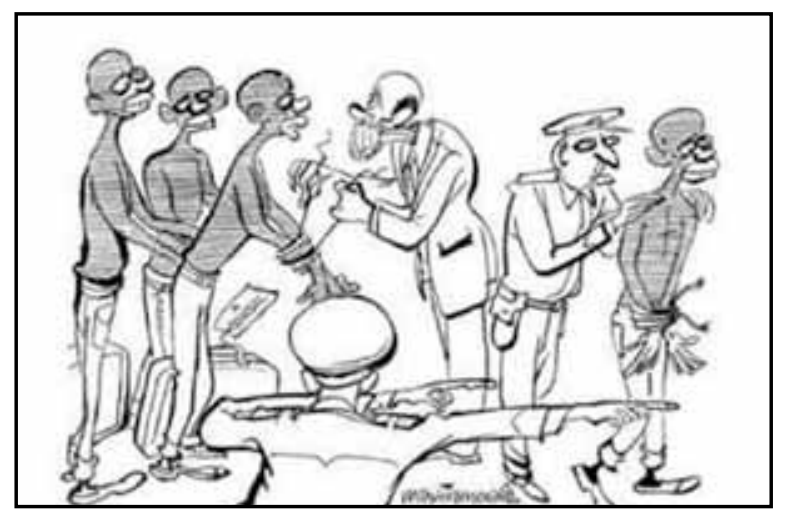

Martín Morales, ABC, 04/06/06.

Modelo referencial. Mediación Política

En torno al mismo hecho, Idígoras y Pachi, en el diario El Mundo, trascienden el acontecimiento específico para situar en un campo de Senegal a un padre que, en la respuesta a su hijo, resume la ausencia de futuro. Aquí la mediación política cede terreno en beneficio de un modelo más conceptual que se centra en la tragedia de la inmigración.

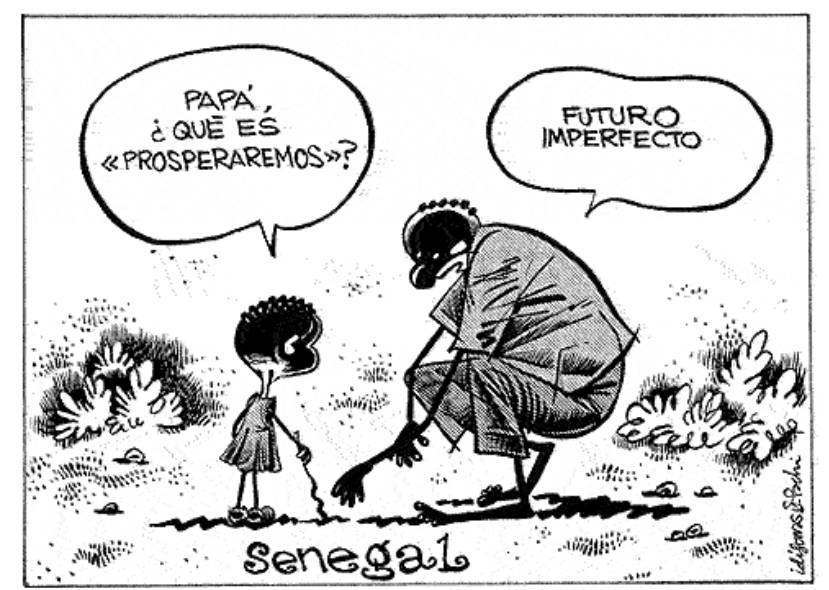

El Mundo, 04/06/06. Modelo conceptual hacia el ambiente social

Finalmente, el dibujante Máximo en el diario El País muestra a un ángel que se pregunta: "Emigrantes, inmigrantes itodos son 
hijos de Dios", a lo que se responde con un lacónico "hum...". También trasciende el acontecimiento para realizar una reflexión más general, sobre la desigualdad.

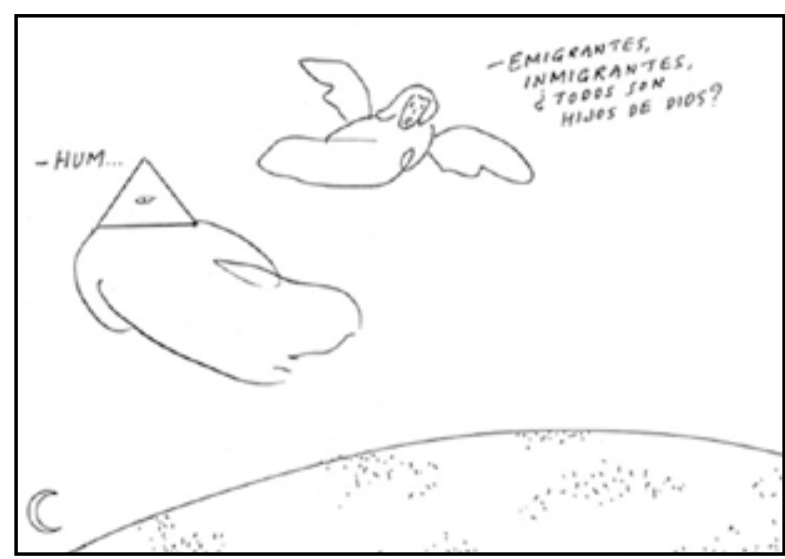

Máximo, El País, 04/06/06.

Modelo conceptual hacia el ambiente social

\subsection{RELIGIONES}

El mismo banco de pruebas es aplicable a la caricaturización en el ámbito de lo religioso, aunque en estos casos supone la necesidad de hacer reconocible a una comunidad religiosa, una práctica o un principio religioso en la viñeta.

A partir del 11-S, en el contexto internacional cobra especial relevancia la variable religiosa con una serie de estereotipos presentes en la opinión iconográfica -un material especialmente fácil de transmitir en red- que invita a una reflexión en un mundo que ya no se puede desprender de las miradas mutuas, basadas en el respeto y no en la intransigencia. La hipótesis de partida es la dificultad de establecer buenas prácticas en un terreno especialmente creativo, la débil línea que separa lo humorístico de lo estereotipador.

Como ocurre con el resto del contenido periodístico referido

10 Trabajos publicados en el monográfico "Humour et médias. Définition, genres et cultures" coordinado por Claude Chabrol presentan la polisemia respecto a las categorías del humor en el discurso periodístico en Questions de Communication 2006, 10, CREM-Metz -Presses Universitaires de Nancy. a lo religioso, resulta complejo representar las creencias con elementos materiales más allá de su plasmación en un comportamiento, una declaración o una costumbre cultural, es decir, a través de la manifestación externa de la creencia, ya sea con una acción o con una declaración. A menudo, en el ámbito religioso suele plasmarse en opciones vitales que se manifiestan en el espacio público a través de la indumentaria, las actitudes o las referencias en el propio discurso.

La visita de Benedicto XVI para asistir a la Jornada Mundial de la Juventud en Madrid, en agosto de 2011, ofrece viñetas en las que el crucifijo es objeto de interpretación burlesca. Como

ejemplo las viñetas del diario Público, muy crítico con la visita papal y la jerarquía eclesiástica.

Al mismo tiempo, es frecuente que en las viñetas se uti-

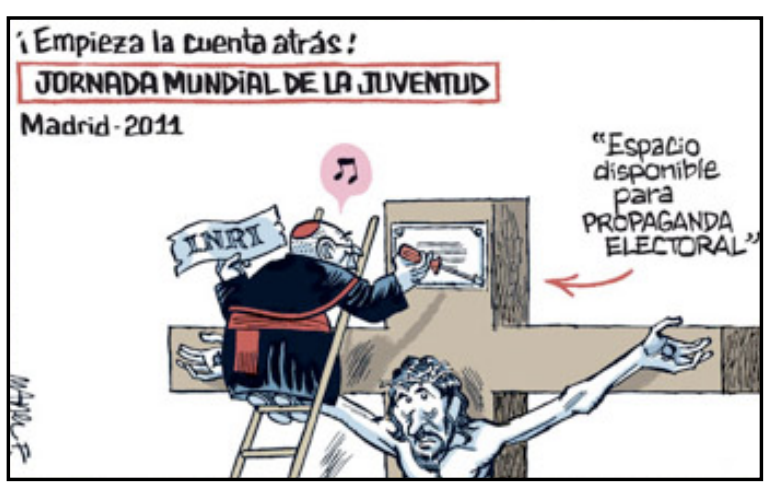

Diario Público,08/2011 visita de Benedicto XVI a Madrid

lice la caricaturización como procedimiento de mímesis, porque es la forma más ágil de representar a un personaje y, sobre todo, de lograr su identificación de forma rápida y segura por parte de todo tipo de lector. Esa caricaturización, sin embargo, supone la distorsión de la realidad, pues lo que se hace es exagerar determinados rasgos (físicos, de comportamiento, formas de vestir o de hablar) con el fin de que el lector los reconozca sin dificultad ${ }^{10}$.

En esta viñeta (El Mundo, 04/09/09), el burka es el símbolo

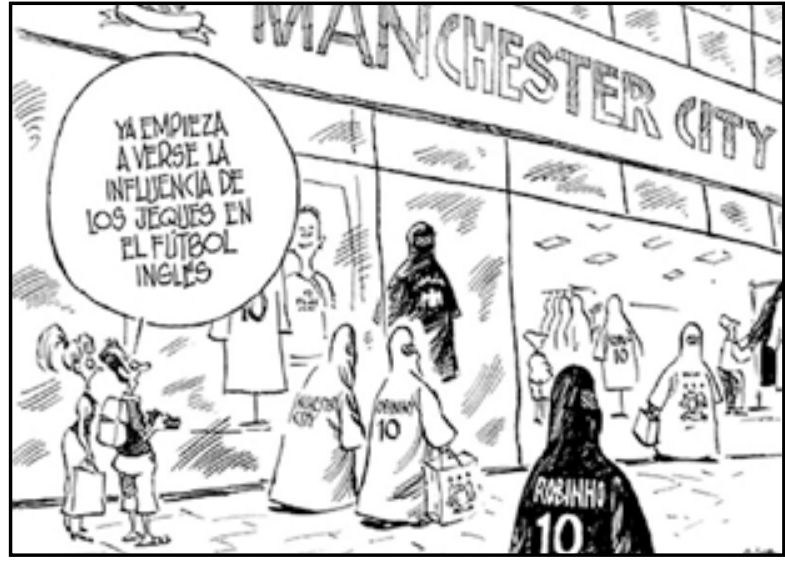

Ricardo, El Mundo, 04/09/09

que representa a la comunidad árabe en Inglaterra. No teniendo la noticia ninguna connotación religiosa, el dibujante, Ricardo, ha intentado sintetizar en ese elemento cultural la representación de una elite económica. Lo curioso no es solo la mezcla 
de liberalismo comercial y rigor religioso que supone este tipo de vestidura, sino que tiene un marcado contexto geográfico pues, en general, es poco frecuente la presencia de este atuendo.

El Observatorio del Antisemitismo en España denunció, en 2009, una viñeta de Manel Fontdevila publicada en el diario Público por la utilización de una simbología religiosa antisemita con la recuperación del mito medieval del deicidio, a través de un personaje (que reúne todas las características del arquetipo negativo del judío: nariz ganchuda, vestimenta hasídica, etc.) que crucifica simbólicamente al nuevo Mesías, Barak Obama, mientras da la espalda a la "paz, amor, concordia, buena voluntad..."

Para analizar la representación de las religiones se selec-

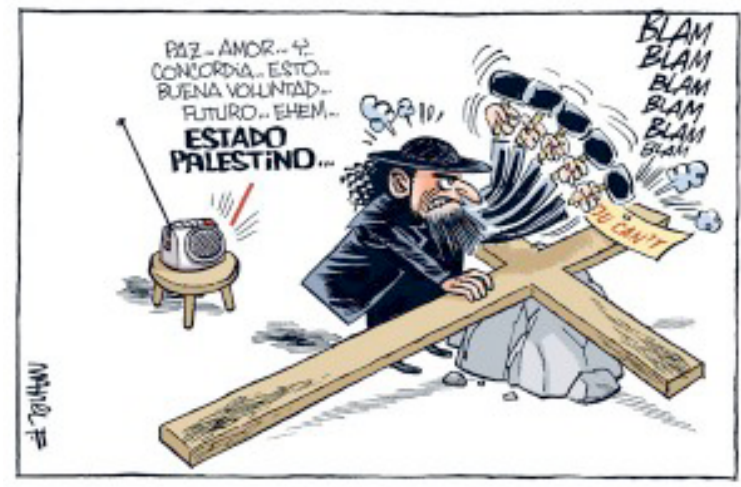

Manel Fontdevila, 2009, diario Público

cionó como referencia el año 2006, porque durante ese año se produjeron distintos acontecimientos relacionados con el tratamiento mediático de lo religioso en un ambiente propiciado por la polémica de las viñetas de la prensa danesa sobre Mahoma. Se recogieron tres episodios: la reacción a las palabras del Papa en Ratisbona (12/09/06-19/09/06), el viaje del Papa a Turquía (28/11/06-01/12/06) y los acontecimientos en el Líbano (12/07/06-14/08/06). Los medios analizados fueron ABC, El Pais y El Mundo, en España; Il Manifesto y Corriere Della Sera, en Italia, así como algunas de las viñetas publicadas en diarios árabes, especialmente en Akhbar Al-Khalij de Bahrein ${ }^{11}$.

Se trata de establecer los principales identificadores que se suelen utilizar en la prensa española e italiana para representar a las tres grandes religiones monoteístas: cristianismo (centrado en el catolicismo), judaísmo e Islam.

Entre los posibles identificadores relacionados con la creencia o la práctica religiosa se pueden apreciar tres niveles o elementos de distinta naturaleza. En primer lugar, aquellos que recogen elementos propios de la religión de carácter perma- nente: símbolos, espacios y edificios de culto, figuras representativas, ritos, y palabras sagradas o conceptos propios. La segunda categoría se refiere a miembros concretos de la comunidad o hechos de actualidad. Y la tercera, incluye aquellas representaciones que recogen rasgos o costumbres en las que se entremezclan elementos culturales y una raíz religiosa. La Tabla 1 puede resultar útil para apreciar los elementos indicados.

Con la diferencia entre los tres niveles es posible averi-

\section{TABLA 1.Elementos identificadores}

\begin{tabular}{|l|}
\hline \multicolumn{1}{|c|}{ Elementos religiosos permanentes } \\
\hline Símbolos \\
\hline Espacios y edificios (se incluyen obras artísticas) \\
\hline Ritos \\
\hline Figuras \\
\hline Palabras o conceptos propios \\
\hline Elementos religiosos no permanentes \\
\hline Personajes \\
\hline Hechos de actualidad \\
\hline Elementos religioso-culturales \\
\hline Indumentaria \\
\hline Comportamientos \\
\hline Otros elementos (físicos, psicológicos...), objetos \\
\hline
\end{tabular}

Fuente: elaboración propia

guar si lo que prima es la representación de la religión o la visión mediatizada de la misma, bien sea a través de quienes la encarnan en el aquí y ahora, o bien confundida con un entorno político o cultural que la distorsiona e incluso la fagocita.

Entre las conclusiones, encontramos referencias que identifican a una comunidad, sobre todo en el formato gráfico, y suponen el riesgo de crear o reforzar estereotipos pues éstos son, fundamentalmente, simplificaciones de la realidad .

La utilización también supone a veces la trivialización de la identidad del otro, el origen o el significado de un determinado rito o de un objeto.

Los símbolos con los que se evoca a las comunidades religiosas -cristianismo, judaísmo e Islam-son: la cruz, para los cristianos; el maguén David, para los judíos y la media luna, para los musulmanes. En ocasiones, algunos dibujantes utilizan el triángulo para representar a la divinidad, sobre la
11 Estas viñetas fueron reproducidas por la AntiDefamation League (ADL) y consultadas en su página web: http://www.adl.org/main_ Arab_World/asam_jun_dec_ bahrain_2006.htm, “Arab Media Review: Anti-Semitism and Other Trends July-December 2006", fecha de consulta: $10 / 01 / 2007$ 
cabeza de un hombre anciano.

La forma de vestir identifica, por lo general, a los distintos colectivos; el problema que se presenta en este punto es la asimilación de lo que es propio de un entorno cultural con una opción religiosa que va más allá de ese espacio. Ejemplo de ello es el burka asociado con el Islam más radical. Por extensión, a veces se extrapola a cualquier tipo de velo que pueda llevar una mujer musulmana como el hiyab.

En el caso de los judíos se produce esa asociación entre la kipá (solideo)/ser judío/ser israelí/y la política exterior de Israel. Cuando se quiere representar a un judío se hace uso de un determinado sombrero: la kipá, las peot (tirabuzones o patillas) en los hombres, barba y hasta la nariz aguileña.

A los musulmanes se les representa con túnicas, chaleco y turbante o fez, así como burka o hijab en las mujeres. En el caso de los católicos, como suelen ser miembros del clero quienes con frecuencia los representan -quizás porque se identifican mejor- su imagen va acompañada de las vestiduras propias como la sotana, la vestidura talar, la estola, la mitra y el capelo cuando son sacerdotes u obispos y todo ello de color blanco y acompañado a veces del báculo, cuando es el Papa.

\section{REFLEXIONES FINALES}

Para analizar las distorsiones que pueden producirse en la caracterización del otro, es necesario introducir el estudio de las variables socioculturales implicadas, entre ellas las más representativas: género, clase social, etnia, religión, origen, edad, apariencia física, enfermedad y orientación sexual.

En dos de las analizadas, el origen y la religión, se pone de manifiesto cómo se produce una caricaturización de determinados rasgos, situaciones, símbolos o gestos con los que se asocia a una comunidad o a una creencia

En el caso del origen, es posible distinguir las viñetas en las que el mensaje se enfoca hacia la mediación política o hacia el sistema social; especialmente en el primer caso se antepone la crítica a la gestión política, mientras que en el segundo se trata de sensibilizar sobre la problemática de un modo más general. La representación gráfica de los inmigrantes es simplificada.

En la variable religiosa, tanto la identificación como la pertenencia se muestran a través del tópico visible y generalizador. Las referencias que identifican a una comunidad religiosa, sobre todo en el formato gráfico, suponen el riesgo de crear o reforzar estereotipos. La utilización también plantea a veces el desconocimiento de la identidad del otro, el origen o el significado de un determinado rito o de un objeto.

Los recursos a lo aparente deben ser revisados y cuestionados, ya que la desfiguración y la descontextualización que los acompañan pueden dificultar la integración y convivencia intercultural.

La actividad de detección de ruidos interculturales debe ser adaptada también a los espacios de la opinión iconográfica, las viñetas o cartoons, por su particular eficacia persuasiva y capacidad sintetizadora. Paradójicamente, estos productos pueden favorecer la sensibilidad social hacia la diferencia o, en el otro extremo, reforzar la distancia y ahondar en los estereotipos.

\section{SOBRE LAS AUTORAS.}

Estrella Israel Garzón, Periodista, doctora en Ciencias de la Comunicación por la Universidad Complutense de Madrid (España). / Profesora de Comunicación y Periodismo Intercultural de la Universidad CEU-Cardenal Herrera de Valencia. Profesora invitada en la Universidad Popular Autónoma de Puebla (México), en la Universidad Austral de Chile, en la Universidad Paul Verlaine de Metz (Francia) y en los encuentros "Interculturalités" de la Universidad Nancy-2. (Francia). / Investiga sobre la dimensión intercultural aplicada a la comunicación. Es la introductora del concepto "periodismo intercultural"./ Autora de Comunicación y Periodismo en una sociedad global. Comunicar la diferencia (2001) y (2006)

Ma José Pou Amérigo, doctora en Ciencias de la Información por la Universidad Complutense de Madrid y Licenciada en Humanidades por la Universitat Oberta de Catalunya. / Profesora de Periodismo en la Universidad CEU-Cardenal Herrera de Valencia. / Autora, entre otros, de Los católicos en la opinión pública. El ejemplo italiano (2008) y Los obispos en la vida pública española. Análisis del diario El País y los conflictos entre el Episcopado y los gobiernos socialistas (2007). 
Abril, N. (1999). Periodismo de opinión, Madrid, Síntesis.

Alvarez Chávez, R. Las ilustraciones de humor y la masculinidad hegemónica tradicional, Investigaciones Sociales Año VIII, 13, 253-274. Lima.

Armañanzas, E. y Diaz Noci, J. (1996). Periodismo y Argumentación, Géneros de Opinión. Bilbao: Servicio Editorial Universidad del País Vasco.

Baer A. y Zuckerman F. (2005). El estigma imborrable, Madrid: Hebraica Ediciones.

Benito, Á. (2001). Diccionario de Periodismo. Madrid: Editorial Acento.

Bergson, H.(1973). La risa. Ensayo sobre la significación de lo cómico. Madrid: Austral

Borrat, H. (1989). El Periódico actor político. Barcelona: Gustavo Gili.

Caldera Serrano, J., Nuño, M.V. (2001). Análisis comparativo de las web de prensa española en Internet, Documentación de las Ciencias de la Información, 24, 195-211.

Camps, V. (2007). Ofensas y Libertad de expresión. Quaderns del Consell del Audiovisual de Cataluña (CAC) 27, 3-12.

Cánovas, J. F. (2003). Los géneros argumentativos. En Diaz Noci, J., Salaverría Aliaga, R. (coords.) Manual de Redacción Ciberperiodística, pp. 525-553. Barcelona: Ariel Comunicación.

Cerezo Arriaga, M. (1994). Texto, contexto y situación. Guía para el desarrollo de las competencias textuales y discursivas. Barcelona: Octaedro.

Chabrol, Claude (Coord.) (2006). Humour et Médias Définitions, genres et cultures. Questions de Communication 10, 7-17.

Chancel, J. (1987), Les dessins de l'actualité. Chêne, France: Relais H.
Duccini, H. (2004). Stereotypes nationaux en Europe Connaissance ou méconaissance de l'autre? Médiamorphoses, 12, 67-71.

Fandos, M. y Martinez, M. J. (1999). Estereotipos en el cómic. Comunicar, 12, 117-119.

Freud, S. (1981). El chiste y su relación con el inconsciente, Obras Completas. Madrid: Aguilar

Gómez Mompart, J.L. (2010). La risa periodística, Valencia: Tirant Lo Blanch.

Goffman, E. (1986). Estigma. La identidad deteriorada. Buenos Aires: Amorrortu.

Gomis, L. (1987). El medio media, La función política de la prensa. Barcelona: Mitre.

Gubern, R. (1997). Medios icónicos de Masas. España: Historia 16

Gubern, R. (2003). Del bisonte a la realidad virtual, La escena y el laberinto. Barcelona: Anagrama.

Herrero Aguado, C. (1997). Periodismo Político y persuasión. Madrid:Actas.

Herrero Aguado, C. (2000). La sustitución de nombres y el humor en el periodismo político. En Espejo Cala, C. (Coord.) Propaganda impresa y construcción del Estado moderno y contemporáneo. Sevilla: Alfar.

Imbert, G. (1988). Le discours du journal. Paris: Éditions du CNRS.

Israel, E. (2001). Comunicación y Periodismo en una Sociedad Global, Comunicar la diferencia. México: Trillas.

Israel, E., Pou, M. J. (2009). La representación de los símbolos religiosos en la opinión iconográfica y su influencia en la simplificación de la realidad. En Jiménez Cataño, R,, Yarza, I. Mimesi, verità, fiction. Ripensare l'arte. Sulla scia della Poetica di Aristotele. Roma: EDUSC. 
Joly, M. (2003). La interpretación de la imagen: entre memoria, estereotipo y seducción. Barcelona: Paidós Comunicación.

Laborda Gil, X. (2002). Ellas y Forges, en el día de la mujer. Ponencia al $V$ Congreso de Lingüistica General, Universidad de León. http://dialnet.unirioja.es/servlet/ articulo? codigo $=1089072$

Maradan, J., Petriccione, D. \& Weill-Sermet, M. (2005). Les déssins de presse: les motifs du succès et l'importance du contexte. Séminaire de Semiologie Graphique, 2005-2006.

Martin, M. (1987), Semiología de la imagen y pedagogía. Madrid: Narcea.

Peñamarín, C. (1997). La imagen dice no. Metáfora e índice en el lenguaje del humor gráfico. La Balsa de la Medusa, 41/42, 91-127.

Peñamarín, C. (2002). El humor gráfico del franquismo y la formación de un territorio translocal de identidad democrática. CIC, 7, 335-380.

Pross, H. (1983). La violencia de los símbolos sociales. Barcelona: Anthropos.
Retis, J. (2004). La imagen del otro: inmigrantes latinoamericanos en la prensa nacional española. Sphera Publica, 4, 119-139.

Rivadeneira, R. (1977). Periodismo. La teoría general de los sistemas y la ciencia de la Comunicación. México: Trillas.

Santamaría, L. (1990). El comentario periodístico. Madrid: Paraninfo.

Tejeiro, R, y Gross, T. L. (2009). Las viñetas de prensa como expresión del periodismo de opinión. Diálogos de la Comunicación, 78. http://www.dialogosfelafacs.net/ revista/articulos-resultado.php?ed=78\&id=106

Tubau, I.(1987). El humor gráfico en la prensa del franquismo. Barcelona: Mitre.

VVAA, (1993) Vamos a reírnos muy en serio del racismo. Madrid: Editorial Presencia Gitana.

Wieviorka, M. (1998). Le racisme. Une introduction. Paris: La Découverte. 